\title{
Tobacco Smoke Exposure Alters Cholesteryl Esterase Activities and Causes Accumulation of Cholesteryl Esters in the Rat Aorta
}

\author{
Fusako Maehira, ${ }^{1, *}$ Ikuko Miyagi, ${ }^{1}$ Nami Kawano, ${ }^{1}$ \\ Mutsumi KaWANo, ${ }^{1}$ and Sumie SHINJOH ${ }^{2}$ \\ ${ }^{1}$ Department of Biochemistry for Health Science and ${ }^{2}$ Department of Nutrition, \\ School of Health Sciences, Faculty of Medicine, University of the Ryukyus, \\ Nishihara, Okinawa 903-01, Japan
}

(Received December 28, 1994)

\begin{abstract}
Summary The mechanism responsible for the atherogenic effects of passive smoking was studied. Four weeks and 12 weeks of exposure of rats to tobacco sidestream smoke resulted in an increase in lipid peroxide contents, expressed as thiobarbituric-acid reactive substances, in lowdensity lipoprotein (LDL) and in aortic tissue. The LDL isolated from plasma exhibited elevations of 136,155 , and $170 \%$ over the control values for TBA, cholesterol, esterified cholesterol, respectively, whereas the corresponding increases in the aorta were 118,148 , and $254 \%$, respective1y. Electrophoretic examinations of LDL revealed a typical denatured LDL. Among esterified cholesterol-metabolizing enzymes in the aorta, lysosomal acid cholesteryl ester hydrolase, microsomal neutral cholesteryl ester hydrolase, and acyl coenzyme A : cholesterol acyltransferase were significantly suppressed by the 4 weeks' exposure; and further suppression of the acid cholesteryl ester hydrolase activity along with increases in the neutral cholesteryl ester hydrolase and acyl coenzyme A : cholesterol acyltransferase activities was observed after 12 weeks' exposure. A possible mechanism of the observed lipid accumulation in the aorta was discussed in connection with the effect of lipid peroxides in oxidatively modified-LDL on esterified cholesterol-metabolizing enzymes.
\end{abstract}

Key Words: passive smoking, oxidatively modified-LDL, cholesteryl esterases, cholesteryl esters, rat aorta

Epidemiological studies [1], autopsy studies [2], and animal experiments [3] have indicated an association between cigarette smoking and coronary heart

\footnotetext{
*To whom correspondence should be addressed.
} 
disease as well as an association between passive smoking and lung cancer $[4,5]$. Particularly, the incidence of atherosclerosis in the abdominal aorta is approximately 8 times higher in smokers than in nonsmokers [6]. It has been widely accepted that the uncontrolled uptake of modified low-density lipoprotein (LDL) by scavenger cells, which are subsequently transformed into the esterified cholesterol (E-CHO)-laden foam cells seen in atherosclerotic plaques, is a plausible mechanism for the pathogenesis of atherosclerosis [7]. Many investigators have predicted that the physiologically most probable form of modified-LDL should be an oxidized-LDL $[8,9]$. There recently appeared an article about the susceptibility of plasma LDL to peroxidation induced by acute smoking [10], in which study the metabolism of LDL by macrophages was used as an indicator for the generation of oxidized-LDL. In the present study, we report the existence of an oxidatively modified-LDL in the blood of rats exposed to mild passive smoking, one that occurs together with an accumulation of E-CHO in the aorta. This is the first report on a possible mechanism for the observed lipid accumulation in the aorta caused by passive smoke: inhibition of intracellular E-CHO-hydrolyzing enzymes, lysosomal acid cholesteryl ester hydrolase (ACEH) and microsomal neutral cholesteryl ester hydrolase (NCEH), by lipid peroxides (LPO) in LDL oxidatively modified by some components of the smoke.

\section{MATERIALS AND METHODS}

Animal experiments. Male Wistar rats 7 weeks of age were exposed to sidestream smoke from cigarettes in an ash tray placed $10 \mathrm{~cm}$ below the rat cage in an exposure box $(50 \mathrm{~L} \times 40 \mathrm{~W} \times 50 \mathrm{H}$ in $\mathrm{cm})$ made of polypropylene, which was placed in a laboratory draft chamber. The cover of the exposure box was half opened, so that the smoke was drawn from the bottom by the fan of the draft chamber. Two groups of 10 rats each were exposed to cigarette smoke (CS) for a $1 \mathrm{~h}$ period twice a day, once in the morning and once in the afternoon, for 4 and 12 weeks. One of these two groups was given $2 \mathrm{mg} \alpha$-tocopherol acetate per rat per day via a stomach tube (CSE group) and the other was not (CS group). A third group of 10 rats, the control group (CSC), was exposed in the same way to atmospheric air, and both CSC and CSE groups were given the same amount of diet intake as the CS group, the appetite of which was reduced by the nicotine in the CS.

Preparation of samples. At 4 and 12 weeks, mononuclear leukocytes (MNL) were isolated from heparinized blood freshly drawn from the rats after $16 \mathrm{~h}$ of fasting, and the LDL and HDL fractions were immediately prepared from the pooled plasma of each group in the presence of antioxidants $(0.05 \%$ glutathione, $0.002 \%$ butylated hydroxyl toluene BHT, and $0.01 \%$ EDTA) [11] by discontinuous density gradient ultracentrifugation at $4^{\circ} \mathrm{C}$ and $250,000 \times g$ for $48 \mathrm{~h}[12,13]$. After dialysis against $1 \mathrm{~mm}$ EDTA in $0.15 \mathrm{M} \mathrm{NaCl}$ containing the antioxidants with the bubbling of $\mathrm{N}_{2}$ gas through the dialyzing solution, the fractions were concentrated 
to $1-8 \mathrm{mg} / \mathrm{ml}$ protein content by the use of Lyphogel (Gelman Instruments). The fractions were stored under $\mathrm{N}_{2}$ at $4^{\circ} \mathrm{C}$ prior to analyses. A portion of the plasma was stained with Sudan Black prior to ultracentrifugation for visualizing the location of lipoprotein bands. After centrifugation, the lipoprotein fractions were collected from unstained preparations while being compared with a prestained preparation. In vitro CS-modified human LDL was prepared according to Yokode et al. [14].

Since one aorta, which weighed about $0.1 \mathrm{~g}$, was not enough for assays, two aortae were homogenized together so that each group was represented by five samples. The $20 \%(\mathrm{w} / \mathrm{v})$ homogenates of pooled aortae of each group were prepared in cold $0.02 \mathrm{M}$ Tris- $\mathrm{HCl}$ buffer, $\mathrm{pH} 7.4$, containing $0.25 \mathrm{M}$ sucrose and 1 mM EDTA by use of a high-speed homogenizer. Liver homogenates $(20 \%, \mathrm{w} / \mathrm{v})$ were also prepared, in which case a Teflon homogenizer was used. The homogenate was extracted twice with chloroform/methanol $(2: 1, \mathrm{v} / \mathrm{v})$ containing $0.002 \%$ BHT. The solvent of the extract was evaporated under $\mathrm{N}_{2}$ at $37^{\circ} \mathrm{C}$, and the residues were dissolved in an aliquot of the same solvent for chemical analyses. The enzyme sources were prepared by centrifuging a part of the aortic homogenate and the hypotonic extracts of MNL with $0.1 \%$ Triton X-100 at $3,300 \times g$ at $4^{\circ} \mathrm{C}$ for $10 \mathrm{~min}$. In the case of liver, the lysosomal and microsomal fractions were respectively obtained by further centrifugation at $12,000 \times g$ for $35 \mathrm{~min}$ followed by $100,000 \times$ $g$ for $100 \mathrm{~min}$. Linoleate hydroperoxide was prepared by air-oxidation and purified by TLC [15]. Statistical analyses were made by comparing mean values and tested by the two-tailed $t$-test.

Biochemical analyses. The content of lipid peroxides was measured fluorometrically [16] and expressed as TBA, with 1,1,3,3-tetraethoxylpropane used as a standard. The lipids were assayed manually by use of commercial kits (Wako, Ltd.) utilizing enzymatic procedures. Agarose electrophoresis was run according to the instructions provided by the manufacturer (Ciba Corning), and the pattern was visualized by staining with Fat Red 7B. SDS-PAGE on 3\% gels was conducted as described by Laemmli [17], and the gel was stained with Coomassie blue G-250. For SDS-PAGE, lipoproteins were delipidated with 40 volumes of ethanol/ethylether $(3: 2, \mathrm{v} / \mathrm{v})$ at $-20^{\circ} \mathrm{C}$ overnight. The lipoproteins in the solvent were mixed briefly and then centrifuged at $800 \times \mathrm{g}$ for $30 \mathrm{~min}$ at $4^{\circ} \mathrm{C}$. Apolipoproteins were dissolved in $0.02 \mathrm{M}$ phosphate buffer, $\mathrm{pH}$ 7.2, containing 1\% SDS and 1\% 2-mercaptoethanol, by incubation at $100^{\circ} \mathrm{C}$ in an oven for $3 \mathrm{~min}$. Apolipoproteins from 50 to $100 \mu \mathrm{g}$ were applied to sample wells.

The activities of ACEH and NCEH were assayed with micellar substrates made of cholesteryl esters of $\left[{ }^{14} \mathrm{C}\right]$-linoleate at $\mathrm{pH} 4.5$ and $\left[{ }^{14} \mathrm{C}\right]$-oleate at $\mathrm{pH} 7.4$, respectively, as described [18], except that the incubation time of $90 \mathrm{~min}$ and the solvent system of Belfrage and Vaughn [19] for extraction of fatty acids were employed. Acyl coenzyme A : cholesterol acyltransferase (ACAT) activity was assayed as described by Billheimer et al. [20]. The enzyme assays for the in vitro inhibition experiments were run as follows: The substrates were added to $10-\mu 1$

Vol. 18, No. 3, 1995 
aliquots of LDL containing the indicated amount of apoprotein, which addition was followed by that of the low-speed aorta supernatant from the CSC group.

\section{RESULTS AND DISCUSSION}

At the end of 4-week and 12-week exposure to tobacco smoke, weight increases in both CS and CSE groups were $69 \%$ of those of the control CSC group, which had been fed the same amount of diet consumed by the CS group. The vitamin E supplementation did not protect against the suppression of weight gain due to a loss of appetite caused by nicotine, but it did have protective effects on the lipid metabolism (Fig. 1 and Table 1). Lipid peroxides expressed as TBA were increased significantly in the blood as well as slightly increased in the aorta. Among plasma lipids, prominent decreases in high-density lipoprotein (HDL)CHO, triglycerides, and phospholipids were observed after 4-weeks' (data not shown) and also after 12-weeks' exposure (Fig. 1). Plasma levels of T-CHO and E-CHO were not altered much, but LDL isolated from plasma showed elevations of 137,155 , and $178 \%$ over the control values for TBA, T-CHO, and E-CHO, respectively; whereas the increases in the aorta from the same group were 118, 148,

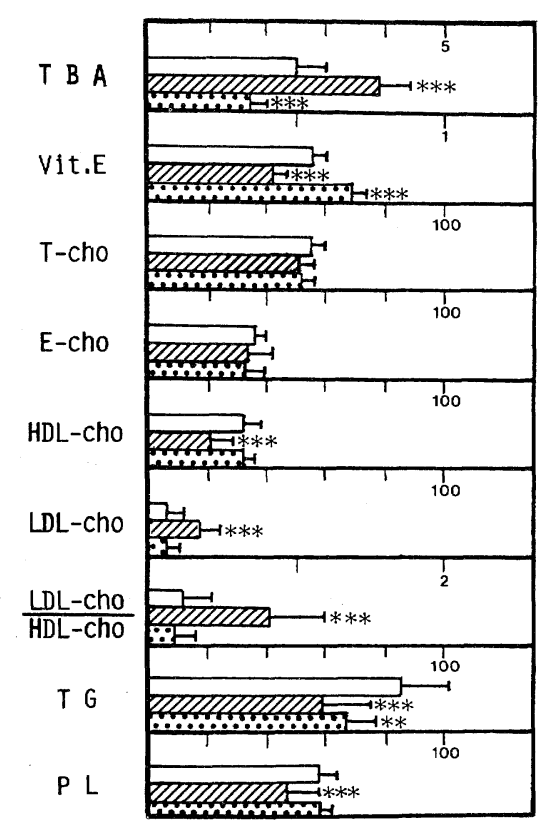

Fig. 1. Analyses of TBA, vitamin E, and lipids in plasma (12-weeks' exposure). Units are expressed as follows: TBA $(\mathrm{nmol} / \mathrm{ml})$, vitamin E and lipids $(\mathrm{mg} / \mathrm{dl})$. Range bars of the CSC group (open columns), the CS group (hatched columns), and the CSE group (stippled columns) represent mean \pm SD. Significant differences at $* * p<0.01$ and *** $p<0.005$ against the control group are indicated. 
Table 1. TBA and lipid analyses of aorta and LDL.

\begin{tabular}{ccccc}
\hline Groups & $\begin{array}{c}\text { TBA } \\
(\mathrm{nmol} / \mathrm{g})\end{array}$ & $\begin{array}{c}\text { T-CHO } \\
(\mathrm{mg} / \mathrm{g})\end{array}$ & $\begin{array}{c}\text { E-CHO } \\
(\mathrm{mg} / \mathrm{g})\end{array}$ & $\begin{array}{c}\text { TG } \\
(\mathrm{mg} / \mathrm{g})\end{array}$ \\
\hline 4-wks' exposure: Aorta & & & & \\
CSC $(n=5)$ & $23.0 \pm 3.4$ & $2.03 \pm 0.20$ & $0.57 \pm 0.24$ & $6.13 \pm 0.50$ \\
& $(100 \%)$ & $(100 \%)$ & $(100 \%)$ & $(100 \%)$ \\
CS $(n=5)$ & $25.0 \pm 3.3$ & $1.60 \pm 0.29^{* *}$ & $0.31 \pm 0.23$ & $6.22 \pm 0.67$ \\
& $(109 \%)$ & $(79 \%)$ & $(54 \%)$ & $(101 \%)$ \\
12-wks' exposure: Aorta & $16.4 \pm 1.7$ & $1.15 \pm 0.20$ & $0.26 \pm 0.08$ & $6.60 \pm 0.60$ \\
CSC $(n=5)$ & $(100 \%)$ & $(100 \%)$ & $(100 \%)$ & $(100 \%)$ \\
CS $(n=5)$ & $19.3 \pm 1.6^{*}$ & $1.70 \pm 0.24^{* *}$ & $0.67 \pm 0.23 *$ & $3.97 \pm 0.55^{* *}$ \\
& $(118 \%)$ & $(148 \%)$ & $(254 \%)$ & $(60 \%)$ \\
CSE $(n=5)$ & $17.7 \pm 2.6$ & $1.49 \pm 0.18^{*}$ & $0.51 \pm 0.16 *$ & $7.34 \pm 1.02$ \\
& $(108 \%)$ & $(130 \%)$ & $(196 \%)$ & $(111 \%)$ \\
12-wks' exposure: LDL & & & $0.81 \pm 0.03$ & $(100 \%)$ \\
CSC & $2.8 \pm 0.21$ & $0.80 \pm 0.05$ & $0.41 \pm 0.06$ \\
CS & $(100 \%)$ & $(100 \%)$ & $(100 \%)$ & $0.73 \pm 0.06$ \\
CSE & $3.8 \pm 0.27$ & $1.24 \pm 0.08$ & $0.73 \pm 0.05$ & $(83 \%)$ \\
& $(137 \%)$ & $(155 \%)$ & $(178 \%)$ & $0.60 \pm 0.04$ \\
\hline
\end{tabular}

Units were expressed per $g$ of tissue for aorta and of protein for LDL. Values shown for LDL are the mean of triplicates $\pm \mathrm{SE} \times 10^{-3}$. Significant difference compared with the control CSC group value: ${ }^{*} p<0.05$ and ${ }^{* *} p<0.005$.

and $254 \%$ for TBA, T-CHO, and E-CHO, respectively (Table 1). These changes were less distinct in the aorta from the 4-weeks' exposure CS group, and the values for $\mathrm{CHO}$ contents were somewhat lower than the control values. The LDL from rats exposed to CS for 4 weeks (CS-LDL) exhibited an increase in the conjugated diene content, which reflects the presence of hydroperoxides (Fig. 2). When expressed by the ratio of the absorbance at $233 \mathrm{~nm}$ to that at $280 \mathrm{~nm}$, CS-LDL gave a value of 7.00 , which was twice that of the control value of 3.39 ; while its TBA value of 21.8 was 8 times greater than the control value of 2.6. The conjugated diene content of CS-LDL in the 12-weeks' exposure rats was 2.69 compared with the control value of 2.04. The spectral absorption of the LDL isolated from 5 ad libitum-fed rats is also presented for reference (Fig. 2).

Electrophoretic examinations revealed a typical denatured LDL in the CS group. This LDL showed an increased electrophoretic mobility, indicating an increase in the net negative charge (Fig. 3A, lane 4; and Fig. 3B, lane 3). The tertiary structure of its apolipoprotein (apo)-B was lost either by alteration to large aggregates forming intra- or inter-molecular crosslinks [21], with malondialdehyde as a bifunctional cross-linking agent [22] such that the aggregates are incapable of entering into the SDS-PAGE gel, or by apo-B fragmentation (Fig. 3C, lane 2) with free radicals present in the lipid portion of the LDL as evidenced by reactivity with TBA and by the conjugated diene content. Similar alterations of

Vol. 18, No. 3, 1995 


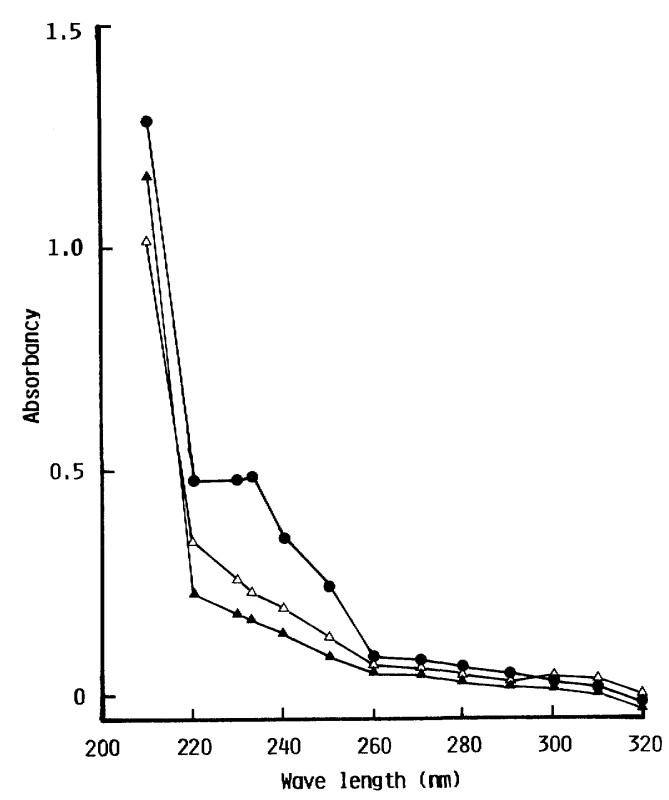

Fig. 2. Absorption spectra of LDL from rats exposed to tobacco sidestream smoke for 4 weeks. A $10-\mu 1$ volume of clear LDL solution after ultracentrifugal separation was immediately extracted with $0.5 \mathrm{ml}$ of absolute ethanol, and the proteins were precipitated by centrifugation at $1,000 \times g$ for $10 \mathrm{~min}$. The spectral absorption of the supernatant was then determined at fixed wavelengths against the blank supernatant. The presence of conjugated diene in the alcohol extract is shown by absorption in the region of 233 nm. •, CS group; $\Delta$, CSC group; $\triangle$, ad libitum-fed rat.

apo-B have been reported based on both in vitro incubation with the CS extract $[14,23]$ and in vivo formation by administrating autoxidized linoleic acid hydroperoxide to rats [23]. The generation of hydroxyl radicals from lipid hydroperoxides present in LDL oxidatively modified in vitro has recently been demonstrated by electron-spin resonance spectrometry [24]. Vitamin E as an antioxidant partially prevented these mobility changes of CS-LDL seen on agarose gel electrophoresis (Fig. 3B, lane 4) and lessened the apo-B fragmentation (Fig. 3C, lane 3) as evidenced by the lack of disappearance of bands as occurred in CS-LDL (lane 2). Although the rat LDL was slightly contaminated with the HDL fraction, a distinct increase in the mobility of CS-LDL was noticed.

As shown in the two-compartment model of E-CHO metabolism in macrophages [7], modified LDL in the circulation is taken up rapidly by specific "scavenger receptors" on macrophages. There are three functional enzymes in this scheme: lysosomal ACEH, which degrades blood-derived exogenous E-CHO to $\mathrm{CHO}$; ACAT, which esterifies $\mathrm{CHO}$ to endogenous $\mathrm{E}-\mathrm{CHO}$ as a storage form by stimulation due to an increase in the intracellular $\mathrm{CHO}$ pool; and microsomal $\mathrm{NCEH}$, which hydrolyzes endogenous E-CHO. All are sensitive to oxidation and are inhibited by thiol reagents [25-27]. We previously reported that the ACEH 
(A)

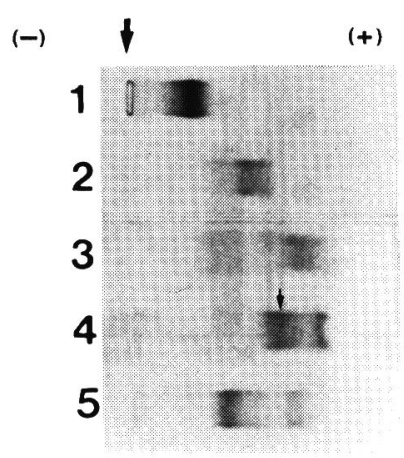

(B)

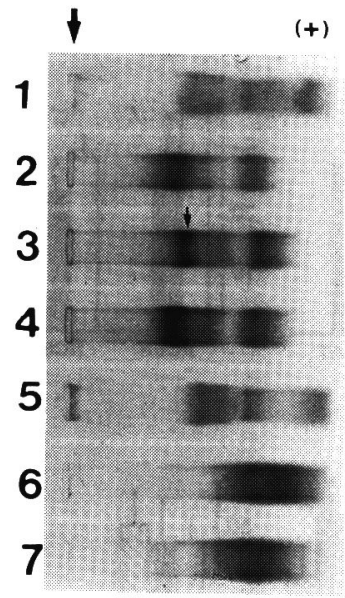

(C)

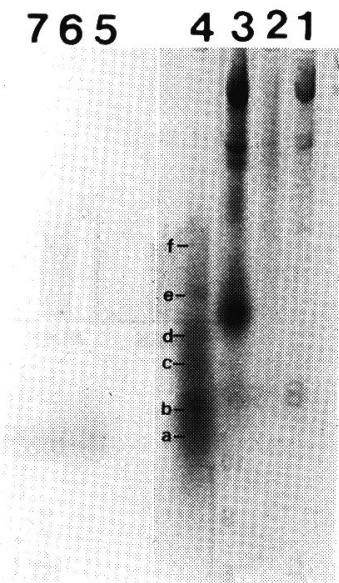

Fig. 3. Electrophoretic studies of LDL (A). Electrophoretic mobility of native and in vivo-modified rat LDL (4-weeks' exposure) on agarose gel in comparison with that of in vitro-modified human LDL prepared with CS-extract. Human LDL in lanes 1 and 2; rat LDL in lanes 3 to 5 ; lane 1, native LDL; lane 2, in vitro CS-modified LDL; lane 3 , plasma from the CSC group; lane 4, LDL from the CS group; lane 5, LDL from the CSC group. (B) Agarose electrophoresis of in vivo-modified rat LDL (12-weeks' exposure). Lanes 1 and 5, plasma from the CSC group; lane 2, LDL from the CSC group; lane 3, LDL from the CS group; lane 4, LDL from the CSE group; lane 6, HDL from the CSC group; lane 7, HDL from the CS group. In (A) and (B), the large arrow indicates the origin; and the small arrow, the in vivo-modified LDL with increased net negative charge. (C) SDS-PAGE of in vivo-modified rat LDL (12-weeks' exposure). LDL from CSC, CS, and CSE groups in lanes 1,2, and 3, respectively; HDL from CSC, $\mathrm{CS}$, and CSE groups in lanes 5,6, and 7, respectively; molecular weight markers in lane 4 (a, 26.6 K; b, 36.5 K; c, $48.5 \mathrm{~K}$; d, $58 \mathrm{~K}$; e, $84 \mathrm{~K} ;$ f, $116 \mathrm{~K}$ ).

activity of MNL was suppressed by elevated LPO in hypercholesterolemic rabbits [12] and humans [13]. During the 4-week exposure, peroxide radicals introduced by the tobacco smoke [28] itself or by pulmonary migratory phagocytic cells such as polymorphonuclear leukocytes [29] and alveolar macrophages [30] in response to cigarette smoking seemed to be mainly trapped in LDL, for the latter gave an extremely high TBA value and conjugated diene content compared with values resulting from the 12-week exposure period. As reported [31], chemically oxidized-LDL introduced into the circulation induces the adhesion of monocytes to arterial endothelium and stimulates their subsequent differentiation into resident macrophages. After oxidized-LDL is taken up by specific high-affinity receptors on those resident macrophages [7] or endothelial cells [32] of the aorta, the activities mentioned above of the three intracellular enzymes would be probably suppressed (shaded columns in Fig. 4A) by the high content of LPO in the oxidatively modified-LDL (Table 1 and Fig. 2), which LDL could probably generate the hydroxyl radical [24]. The lower aortic E-CHO content in the 4 weeks' exposure 
A
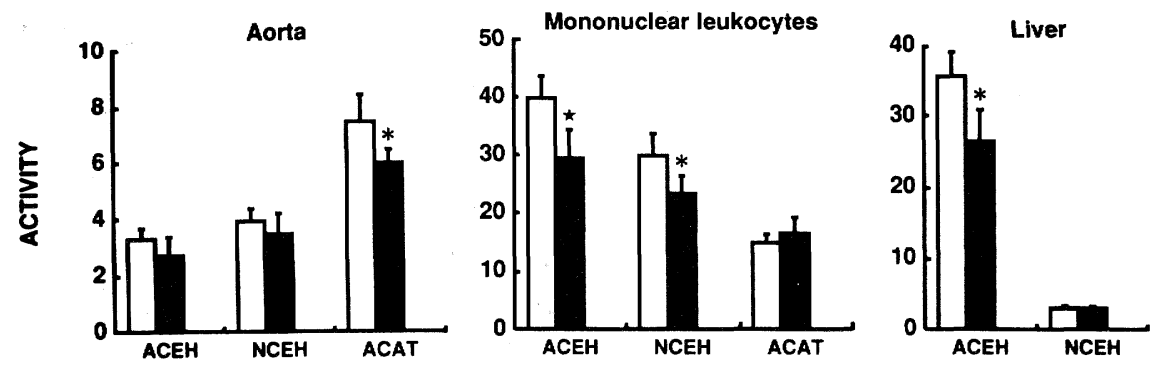

B
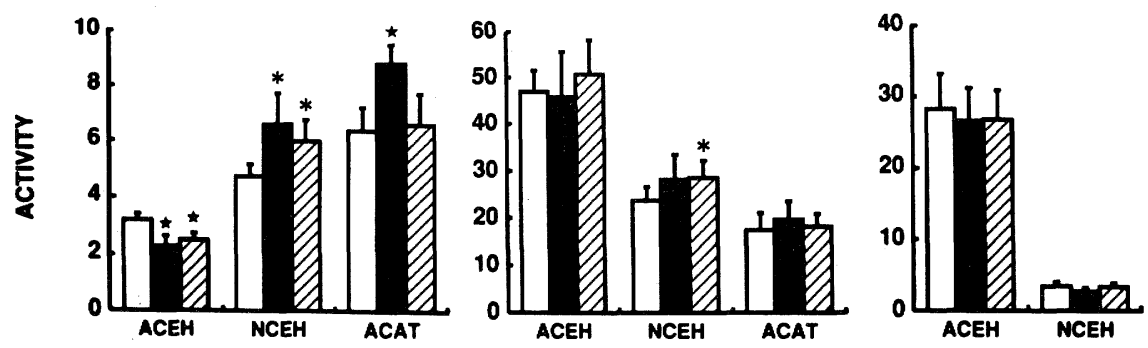

Fig. 4. Cholesteryl ester-hydrolyzing and -synthesizing activities of aorta, mononuclear leukocytes, and liver. (A) 4-week exposure; (B) 12-week exposure. The height of the columns represents the specific activity in $\mathrm{nmol} / \mathrm{h}$ per $\mathrm{mg}$ of protein. The range bars of the CSC (open columns), CS (shaded columns), and CSE (hatched columns) groups indicate the mean $\pm \mathrm{SD}$. Significant differences at ${ }^{*} p<0.05$ and ${ }^{\star} p<0.005$ against the control CSC group are indicated.

CS group than in the control (Table 1) can probably be attributed to the lower ACAT activity (Fig. 4A). By 12 weeks of exposure, through the elimination of denatured-LDL by a mechanism involving monocytes/macrophages in the aorta, the production and elimination of oxidized-LDL might have reached an equilibrium, giving a 1.4-fold higher TBA value for the CS-LDL over the CSC-LDL one compared with the 7.8 -fold difference at 4 weeks.

By 12 weeks of exposure (Fig. 4B), ACEH, which hydrolyzes blood-derived exogenous E-CHO, had become suppressed, allowing an intracellular increase in exogenous $\mathrm{E}-\mathrm{CHO}$ and free $\mathrm{CHO}$. This free $\mathrm{CHO}$ stimulated ACAT so that the endogenous E-CHO could be also increased. These increases in both exogenous and endogenous E-CHO resulted in the $254 \%$ increase over the control value (Table 1). Such an intracellular increase in E-CHO subsequently stimulated the activity of $\mathrm{NCEH}$, which was $140 \%$ of the control (Fig. 4B). The degree of actual stimulation of NCEH as well as ACAT might be far greater than that observed because the increased activity was obtained in the presence of LPO, which may generate the hydroxyl radical [24] and inhibit the enzyme activity. The E-CHOmetabolizing enzymes in MNL, which cells are constantly exposed to the blood 


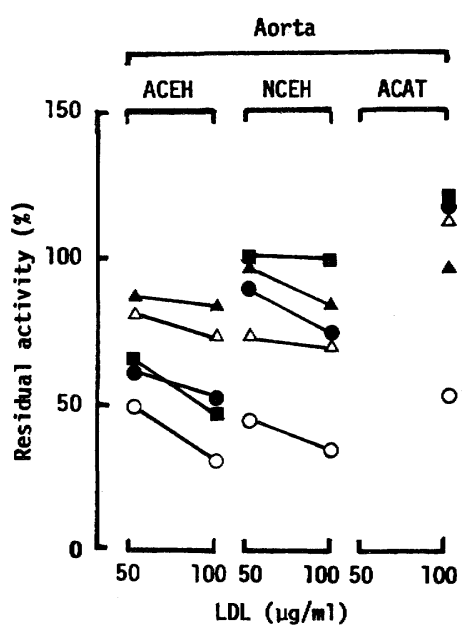

Fig. 5. In vitro effects of rat LDL isolated from aortae of the 4-week exposure (open symbols) and 12-week exposure (closed symbols) groups on aortic activities of hydrolytic and synthetic enzymes of E-CHO from the CSC group. The percentages of the residual activity of hydrolases decreased with an increase in the amount of LDL added to the assay system, whereas the synthetic activity was stimulated by the addition of LDL from the two CS groups. Symbols: triangles, CSC; circles, CS; and squares, CSE. Values shown are the mean of triplicate assays. The control activities were 2.97, 2.68, and $9.66 \mathrm{nmol} / \mathrm{mg} / \mathrm{h}$ for $\mathrm{ACEH}, \mathrm{NCEH}$, and ACAT, respectively.

and are thereby influenced by the blood constituents, also exhibited similar changes but of lesser degree than the enzymes in the aorta. The same enzymes in the liver, which is a major organ for the scavenging of free radicals increased in the blood, were also affected to some extent.

The changes in the three functional enzymes in the macrophage receptor system that were observed in vivo (Fig. 4) were confirmed in vitro (Fig. 5). The CS-LDL from the 4- and 12-week exposure CS groups inhibited the two hydrolytic activities of the aorta most efficiently among the LDL's isolated from the three groups when increased amounts of it were added. Stimulative effects on ACAT were confirmed by the addition of LDL from the 12-week exposure CS and CSE groups, whereas an inhibitory effect on ACAT by CS-LDL from the 4-week exposure group was also obtained, probably due to its high LPO content.

Tobacco smoke is a rich source of oxidizing agents including a variety of radicals [33] and oxides of nitrogen [28]. One of the pulmonary disturbances caused by these radicals of tobacco smoke is pulmonary emphysema due to oxidative inactivation of $\alpha_{1}$-proteinase inhibitor [34]. In this present report, as one of the mechanisms for atherosclerosis in relation to passive smoking, an oxidative inactivation of intracellular E-CHO-hydrolyzing enzymes by free radicals in LDL as an oxidized form was demonstrated. 
This work was supported in part by a grant from Mitsui Life Social Welfare Foundation.

\section{REFERENCES}

1. Wilhelm, L. (1988): Coronary heart disease: Epidemiology of smoking and intervention studies of smoking. Am. Heart J., 115, 242-249.

2. Viel, D., Donoso, S., and Salcedo, D. (1968): Coronary atherosclerosis in person dying violently. Arch. Intern. Med., 122, 97-103.

3. Auerbach, O., Carter, H.W., Garfinkel, L., and Hamond, C.E. (1976): Cigarette smoking and coronary artery disease. A macroscopic and microscopic study. Chest, 70, 697-705.

4. Pittilo, R.M., Mackie, J.J., Rowles, P.M., Machin, S.J., and Woolf, N. (1982): Effects of cigarette smoking on the ultrastructure of rat thoracic aorta and its ability to produce prostacyclin. Thromb. Haemostasis, 48, 173-176.

5. Hirayama, T. (1983): Passive smoking and lung cancer: Consistency of association. Lancet, 2, 1425-1426.

6. Auerbach, O., and Garfinkel, L. (1980): Atherosclerosis and aneurysm of aorta in relation to smoking habits and age. Chest, 78, 805-809.

7. Brown, M.S., and Goldstein, J.L. (1983): Lipoprotein metabolism in macrophage: Implications for cholesterol deposition in atherosclerosis. Annu. Rev. Biochem., 52, 223-261.

8. Steinbrecher, U.P., Parthasarathy, S., Leake, D.S., Witztum, J.L., and Steinberg, D. (1984): Modification of low density lipoprotein by endothelial cells involves lipid peroxidation and degradation of low density lipoprotein. Proc. Natl. Acad. Sci. U.S.A., 81, 3883-3887.

9. Heinecke, J.W., Rosen, H., Suzuki, L.A., and Chait, A. (1987): The role of sulfur-containing amino acids in superoxide production and modification of low density lipoprotein by arterial smooth muscle cells. J. Biol. Chem., 262, 10093-10103.

10. Harats, D., Ben-Naim, Y., Dabach, Y., Hollander, G., and Havivi, E., Stein, O., Stein, Y. (1990): Effect of vitamin C and E supplementation on susceptibility of plasma lipoproteins to peroxidation induced by acute smoking. Atherosclerosis, 85, 47-54.

11. Lee, D.M., Valente, A.J., Kuo, W.H., and Maeda, H. (1981): Properties of apolipoprotein in urea and in aqueous buffers. The use of glutathione and nitrogen in its stabilization. Biochim. Biophys. Acta, 661, 133-146.

12. Maehira, F., Miyagi, I., Nagamine, J., and Khono, S. (1990): Reversible inhibitory effects of apo-B-carrying lipoproteins on acid lipase activity of mononuclear leukocytes from cholesterol-fed rabbits. J. Clin. Biochem. Nutr., 9, 103-114.

13. Maehira, F., Miyagi, I., Kohno, S., and Nakada, F. (1991): Possible inhibitory effect of lipid peroxides via low-density lipoprotein on acid lipase activity in human mononuclear leukocytes. J. Clin. Biochem. Nutr., 11, 129-138.

14. Yokode, M., Kita, T., Arai, H., Kawai, C., Narumiya, S., and Fujiwara, M. (1988): Cholesteryl ester accumulation in macrophages incubated with low density lipoprotein pretreated with cigarette smoke extract. Proc. Natl. Acad. Sci. U.S.A., 85, 2344-2348.

15. Gamage, P.T., Mori, T., and Matsushita, S. (1971): Effect of linoleic acid hydroperoxides and their secondary products on the growth of Escherichia coli. Agric. Biol. Chem., 35, 3339.

16. Yagi, K. (1976): A simple fluorometric assay for lipoperoxide in blood plasma. Biochem. Med., 15, 212-216.

17. Laemmli, U.K. (1968): Cleavage of structural protein during the assembly of the head of bacteriophage T4. Nature, 227, 680-685.

18. Shinomiya, M., Matsuoka, N., Shirai, K., Saito, Y., and Kumagai, A. (1979): Studies on cholesterol esterase in rat arterial wall. Atherosclerosis, 33, 343-350.

19. Belfrage, P., and Vaughn, M. (1969): Simple liquid-liquid partition system for isolation from mixtures with glycerides. J. Lipid Res., 10, 341-344.

20. Billheimer, J.T., Tavani, D., and Nes, W.R. (1981): Effect of dispersion of cholesterol in 
Triton WR-1339 on acyl CoA : cholesterol acyltransferase in rat liver microsomes. Anal. Biochem., 111, 331-335.

21. Chio, K.S., and Tappel, A.L. (1969): Inactivation of ribonuclease and other enzymes by peroxidizing lipids and malonaldehyde. Biochemistry, 8, 2827-2832.

22. Wold, F. (1972): Bifunctional reagents. Methods Enzymol., 25, 623-651.

23. Maehira, F., Yonaha, M., Nakazono, N., Miyagi, I., and Shinjoh, S. (1994): In vivo formation of oxidatively modified low-density lipoprotein and its inhibitory effects on cholesteryl ester hydrolases in the rat. J. Clin. Biochem. Nutr., 16, 37-50.

24. Yagi, K., Komura, S., Ishida, N., Nagata, N., Kohno, M., and Ohishi, N. (1993): Generation of hydroxyl radical from lipid hydroperoxides contained in oxidatively modified lowdensity lipoprotein. Biochem. Biophys. Res. Commun., 190, 386-390.

25. Takano, T., Black, W.J., Peters, T.J., and De Duve, C. (1974): Assay, kinetics, and lysosomal localization of an acid cholesteryl esterase in rabbit aorta smooth muscle cells. J. Biol. Chem., 249, 6732-6737.

26. Kothari, H.V., Bonner, M.J., and Miller, B.F. (1970): Cholesterol ester hydrolase in homogenates and lysosomal fractions of human aorta. Biochim. Biophys. Acta, 202, 325331 .

27. Norum, K.R., Helgerud, P., and Lilljequist, A.C. (1981): Enzymatic esterification of cholesterol in rat intestinal mucosa catalyzed by acyl-CoA : cholesterol acyltransferase. Scand. J. Gastroenterol., 16, 401-410.

28. Pryor, W.A., Tamura, M., Dooley, M.M., Premovic, P., Hales, B.J., and Church, D.F. (1983): Reactive oxy-radicals from cigarette smoke and their physiological effects, in Oxy Radicals and Their Scavenger Systems, Vol. II, ed. by Greenwald, R.A., and Cohen, G., Elsevier Scientific Publishing Co., Inc., Amsterdam, pp. 185-192.

29. Bridges, R.B., Wyatt, R.T., and Rehm, S.R. (1985): Effect of smoking on peripheral blood leukocytes. Eur. J. Respir. Dis., 66, 24-33.

30. Hoidal, J.R., Fox, R.B., Lemarbe, P.A., Perri, R., and Repine, J.E. (1981): Altered oxidative metabolic responses in vitro of alveolar macrophages from asymptomatic cigarette smokers. Am. Rev. Respir. Dis., 123, 85-89.

31. Frostegård, J., Nilson, J., Haegerstrand, A., Hamsten, H., Wigzell, H., and Gidlund, M. (1990): Oxidized low density lipoprotein induces differentiation and adhesion of human monocytes and the monocytic cell line U937. Proc. Natl. Acad. Sci. U.S.A., 87, 904-908.

32. Stein, O., and Stein, Y. (1980): Bovine aortic endothelial cells display macrophage-like properties towards acetylated ${ }^{125}$ I-labelled low density lipoprotein. Biochim. Biophys. Acta, 620, 631-635.

33. Pryor, W.A. (1980): Methods of detecting free radicals and free radical-mediated pathology in environmental toxicology, in Molecular Basis of Environmental Toxicity, ed. by Bhatnagar, R.S., Ann Arbor Science, Michigan, pp. 3-36.

34. Janoff, A. (1983): Biochemical links between cigarette smoking and pulmonary emphysema. J. Appl. Physiol, 55, 285-293. 